\title{
Evaluation of Learning in Performance of Shahroud University of Medical Sciences Hospitals by Using European Foundation for Quality Management Criteria in Setting Balanced Scorecard Indicators
}

Mohammad Yahyaei $^{{ }^{*}}$, Seyed Ali Akbar Ahmadi², Pirhossein Koulivand ${ }^{3}$, Mojtaba Rajab Beygi ${ }^{1}$

${ }^{1}$ Department of Public Administration, Faculty of Management, Payame Noor University, Tehran, Iran ${ }^{2}$ Department of Public Administration, Faculty of Management, Center of West Tehran, Payame Noor University, Tehran, Iran ${ }^{3}$ Department of Organizational Behavior Management, Faculty of Management, Payame Noor University, Tehran, Iran

\begin{tabular}{|c|c|c|}
\hline & Article Info: & \\
\hline Received: 4 Dec 2018 & Revised: 30 Dec 2018 & Accepted: 13 Jan 2019 \\
\hline
\end{tabular}

\section{ABSTRACT}

Introduction: Balanced scorecard (BSC) is one of the best and most used models for evaluating the performance in hospitals, which deals with four evaluation points and learning is one of them. To use this model, a conceptual model should be provided to develop a set of performance indicators in line with the hospital strategy goals. The purpose of this study was to investigate the role of learning in assessing the performance of Shahroud hospitals by using the European Foundation for Quality Management (EFQM) criteria in the regulation of BSC indices. Materials and Methods: A simple random sampling method was used for this survey. The statistical population includes all employed and admitted patients in Imam Hossein and Bahar hospitals in the year 2018. Sample size in Imam Hussein Hospital was 700 and in the Bahar hospital was 200 people. To collect data, four separate questionnaires were used based on the four criteria of BSC, the EFQM criteria, and the standard SERVQUAL ques tionnaire. Content validity of the questionnaires was confirmed by 11 experts in the treatment and accreditation group of hospitals (professors and senior management experts). Results: By reviewing the BSC sights and the relationship between their goals, the perspective of the squadrons was at the best level and in the order of progress, financial and growth and learning was at the lowest level. Increasing employee satisfaction and encouraging innovation as the most basic goal and patient satisfaction from the physical environment was at the highest level of the strategy map. Conclusion: This method, in addition to providing a new aspect for determining the BSC indices, accurately revealed that investment in the field of growth and learning is very important. This is important as they ultimately are the members that affect the processes and outcomes of the organization and achieve the goals of other landscapes and reach the outlook of the hospital. Furthermore, it is recommended that hospital managers use common indicators between $\mathrm{BSC}$ and $\mathrm{EFQM}$ to facilitate the implementation of accreditation in hospitals.

Key words:

1. Learning

2. Hospitals

3. Patients

*Corresponding Author: Mohammad Yahyaei

E-mail: yahyaei@shmu.ac.ir 


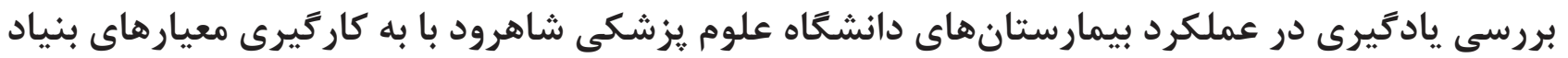

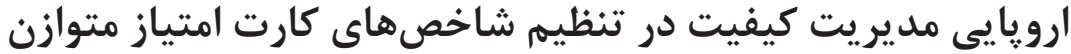

\author{
محمد يحيايى'"، سيد على اكبر احمدى '، ييرحسين كوليوند"، مجتبى رجب بيكى' \\ 'كروه مديريت دولتى، دانشكده مديريت، دانشعاه پِيام نور، تهران، ايران \\ كَروه مديريت دولتى، دانشكده مديريت، مركز تهران غرب، دانشكاه يِام نور، تهران، ايران

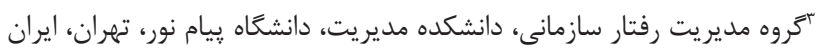

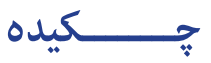

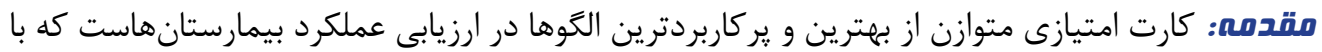

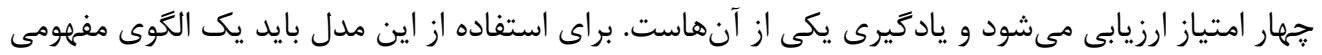

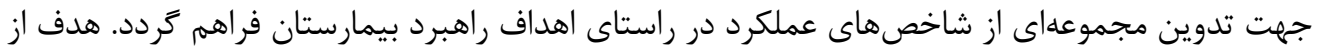

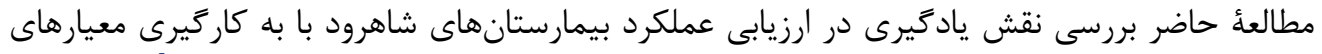

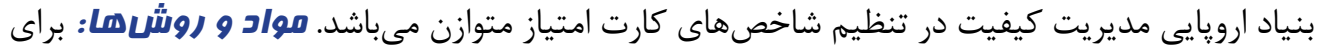

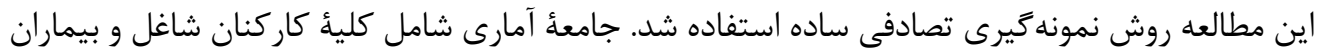

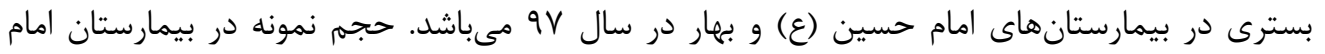

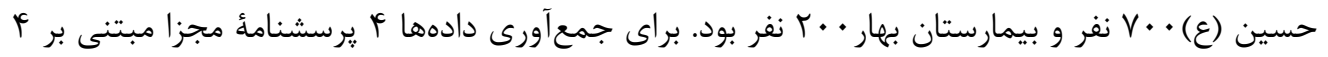

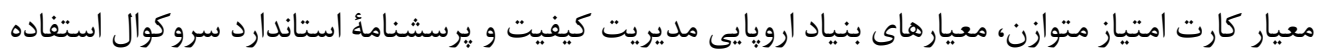

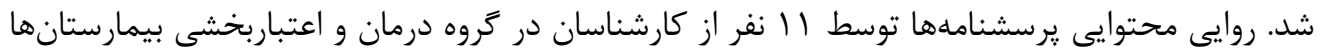

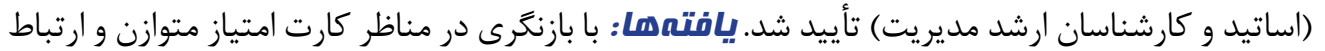

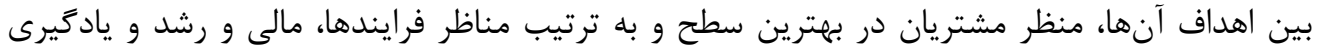

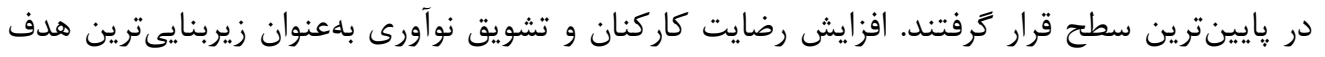

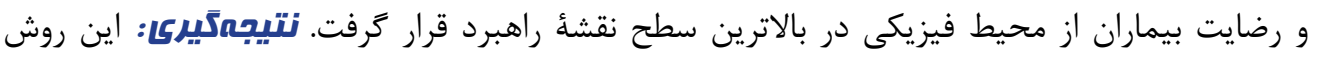

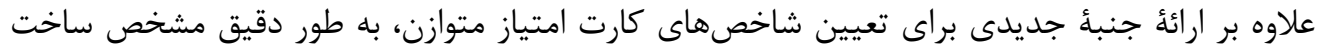

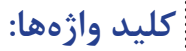

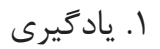

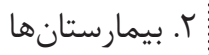

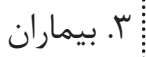

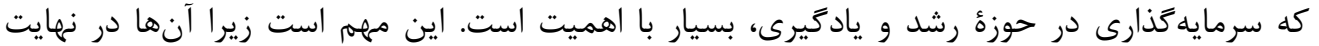

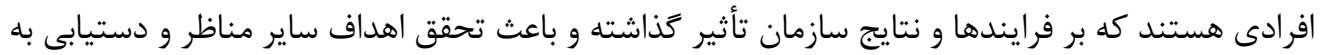

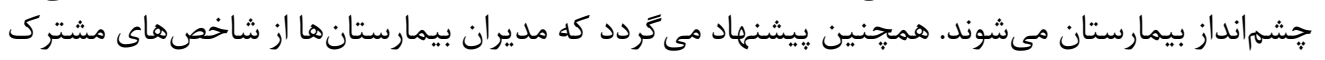

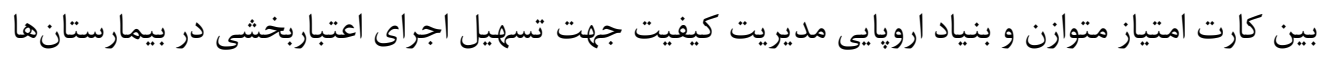




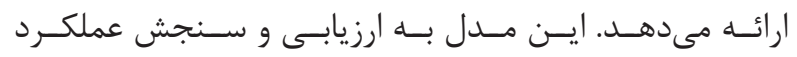

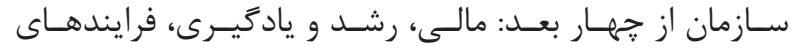

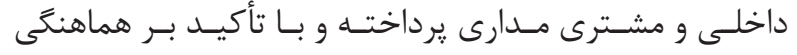

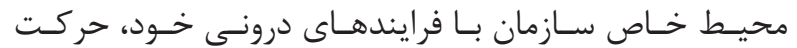

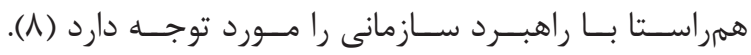

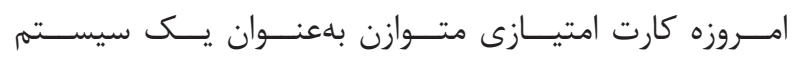

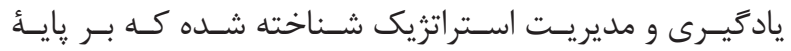

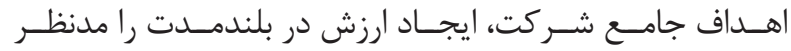

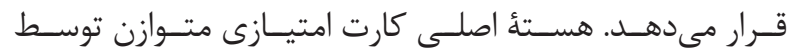

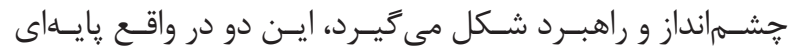

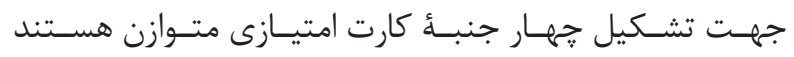

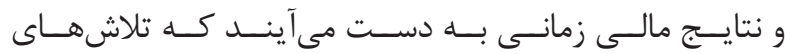

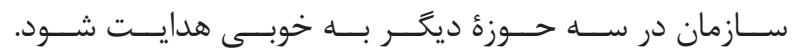

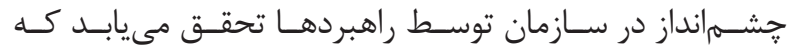

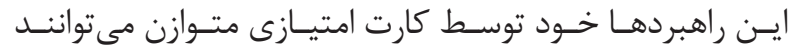

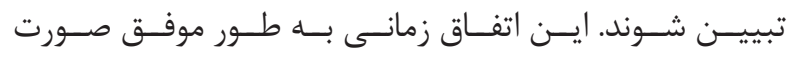

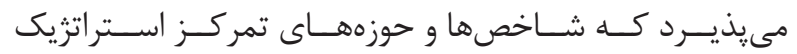

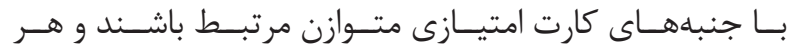

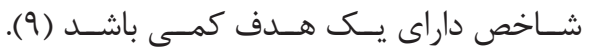

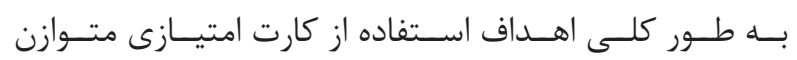

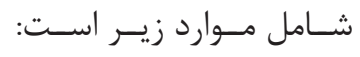

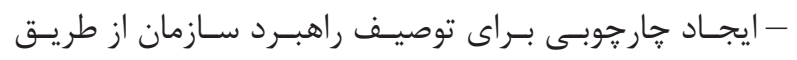

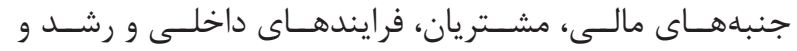
ياد گيـرى.

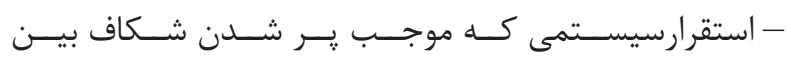

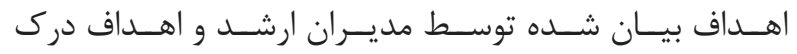

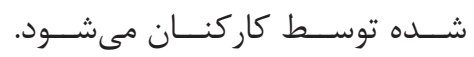

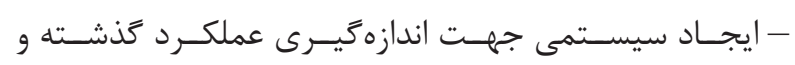
هدايـت عملكــرد آينــده ( •(1).

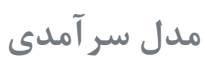
در سـال 911 الميـلادى جهـارده شـركت معتبــر ارويايسى بــا

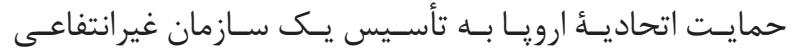

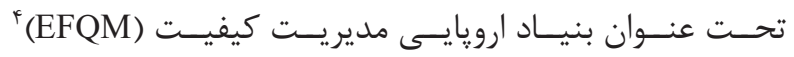

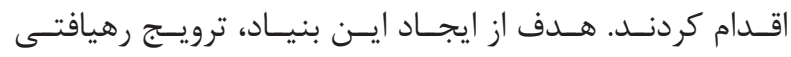

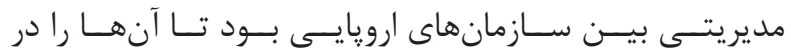

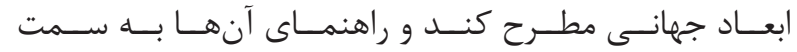

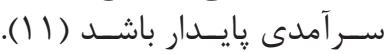
مـدل سـرآمدى EFQM يـك مــدل غيـر تجويـزى اسـت كـهـ

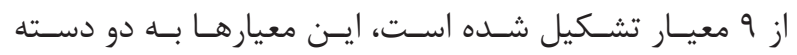

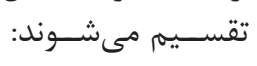

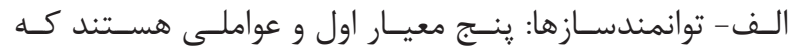

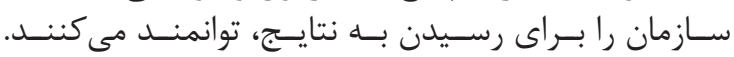
ب- نتايــج: نتايجــى هســتند كــه ســازمان ســرآمد در

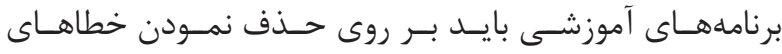

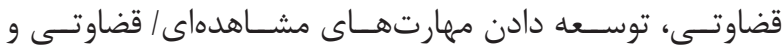

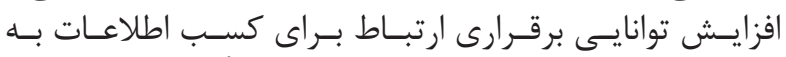

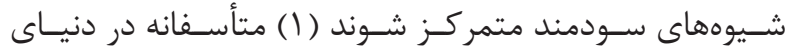

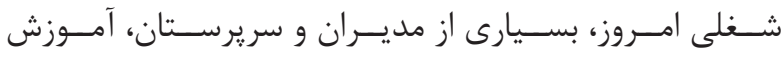

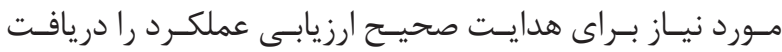

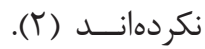

از طـــرف ديخـــر ســازمانها در عصـــر امــروز روز بـــهـ روز

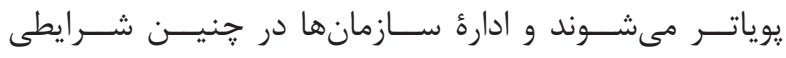

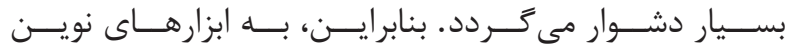

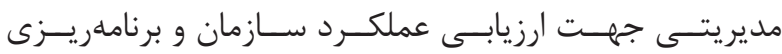

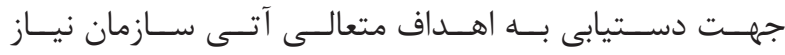

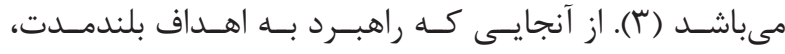

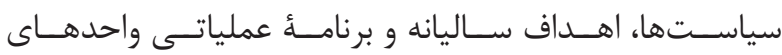

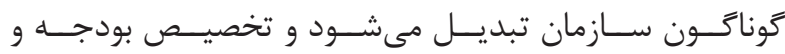

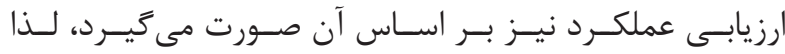

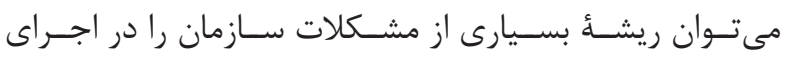

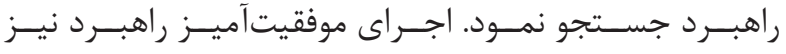

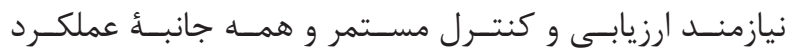

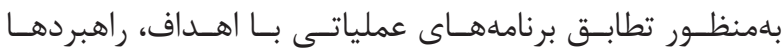

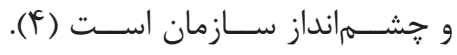

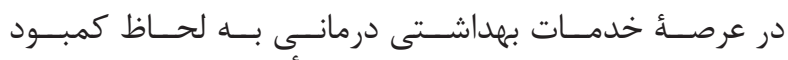

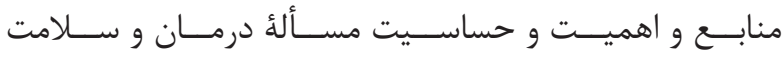

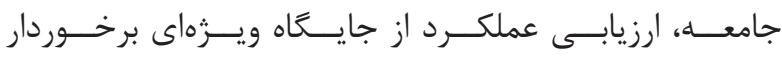

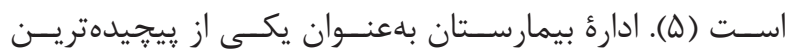

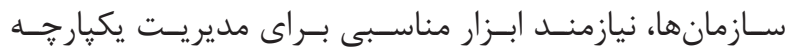

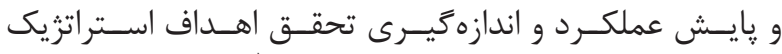

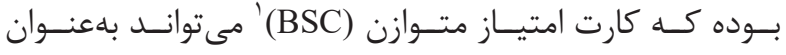

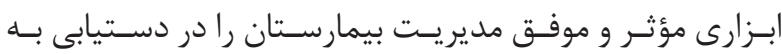

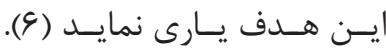

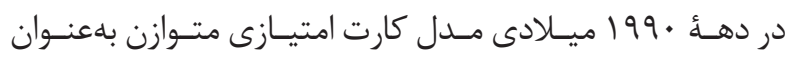

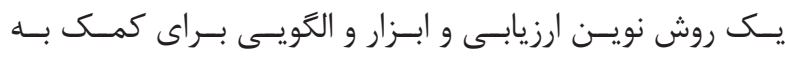

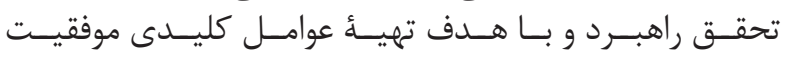

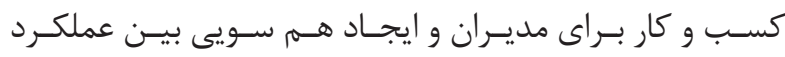

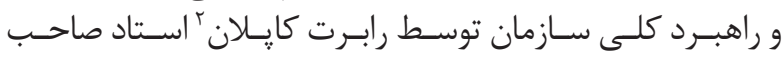

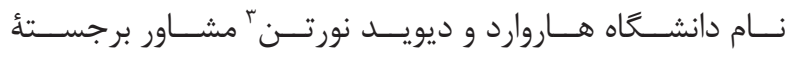

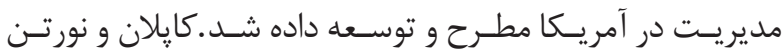

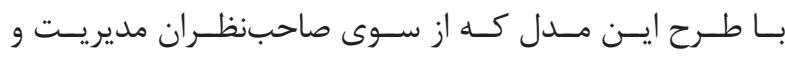

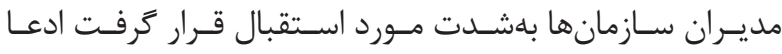

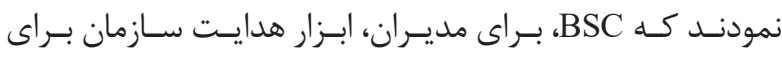

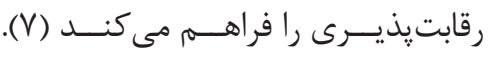

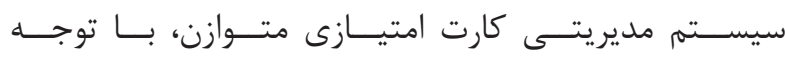

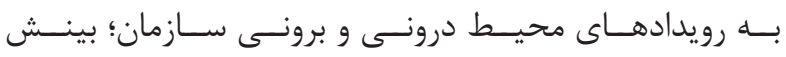

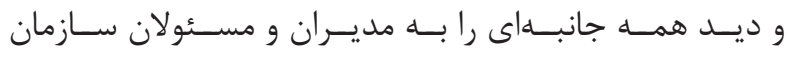

${ }^{3}$ David Norton

${ }^{4}$ European foundation of quality management 


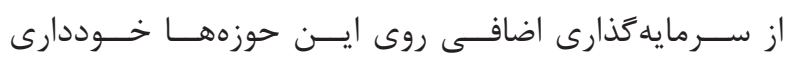

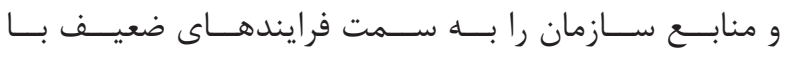

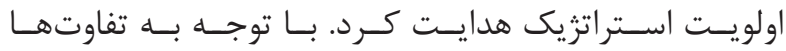

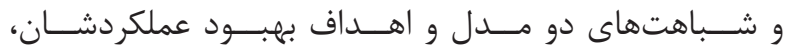

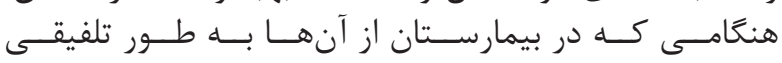

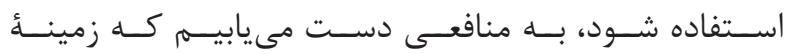

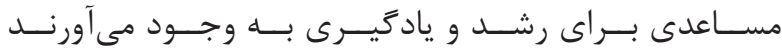

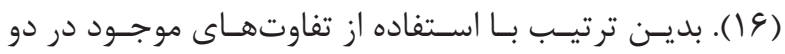

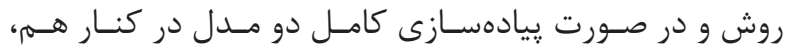

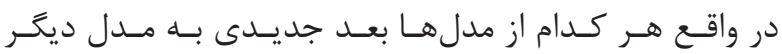

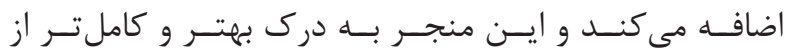

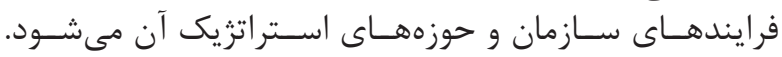

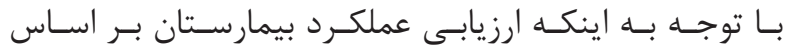

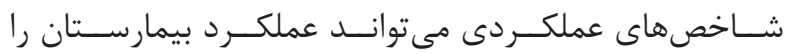

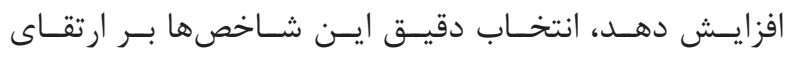

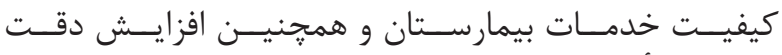

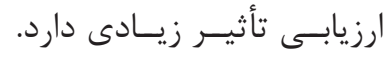

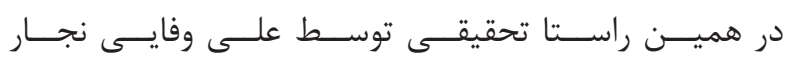

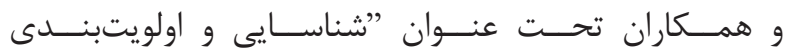

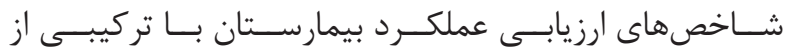

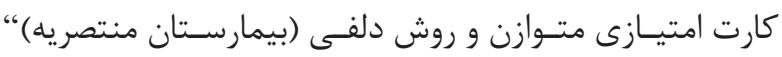

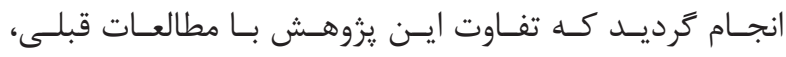

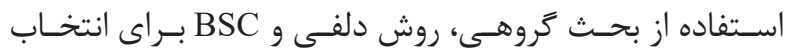

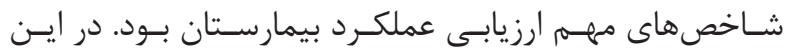

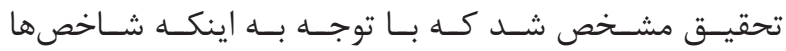

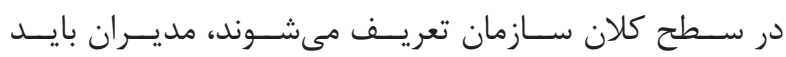

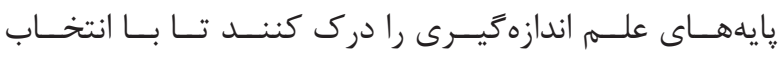

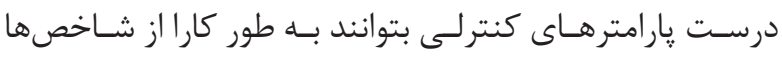

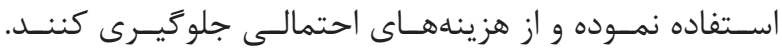

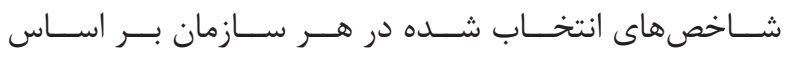

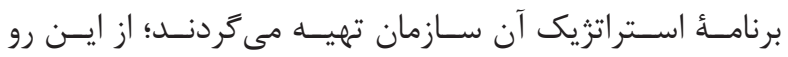

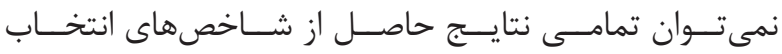

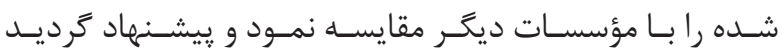

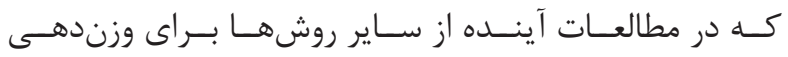

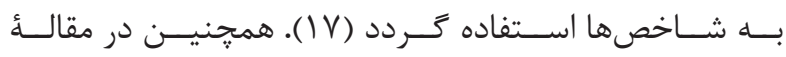

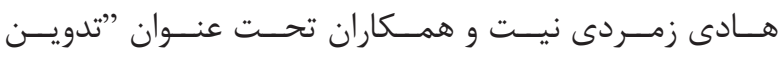

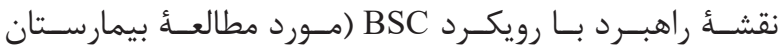

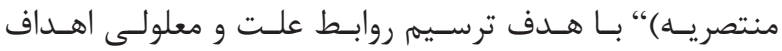

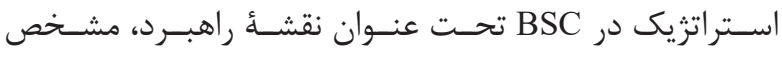

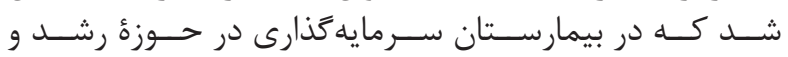

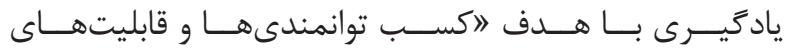

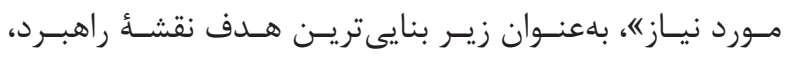

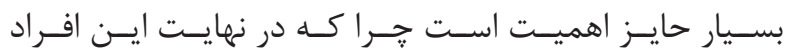

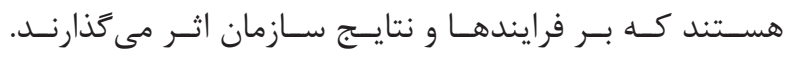

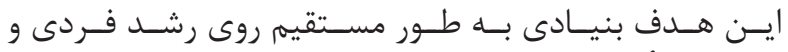

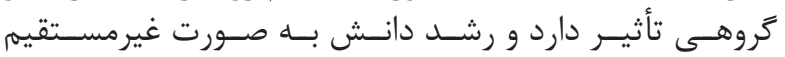

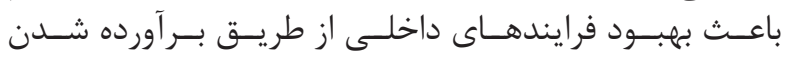

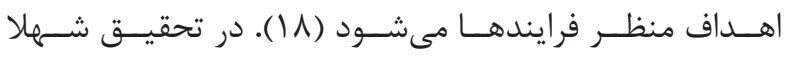

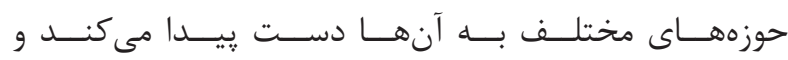

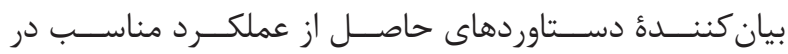

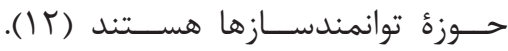

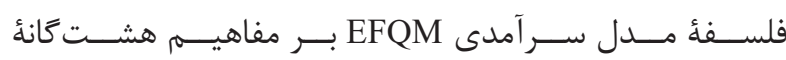

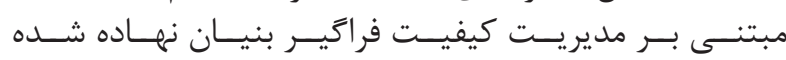

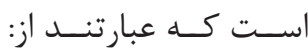

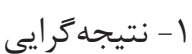

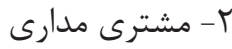

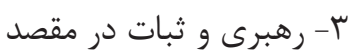

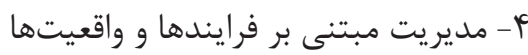

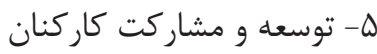

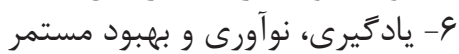

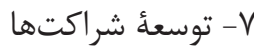

人- مسئوليت اجتماعى (1) - (I).

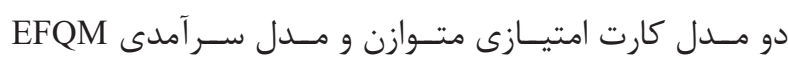

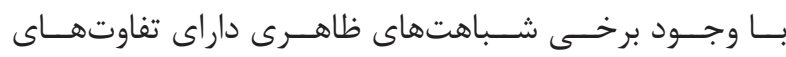

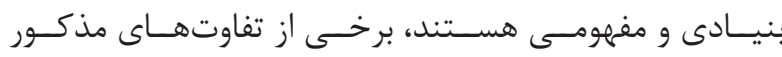
عبارتنــد ازئ و

- اسـتقلال از محيـط در مـدل EFQM و وابسـتخى بـــ آن در

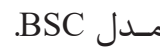

- توصيفى بودن مدل EFQM و متمركز بودن مدل BSC EFQM (انتزاعى) اسـت.

- مــدل EFQM نشـاندهنده وضعيـت جــارى اسـت و مـدل

نمايانغـر وضعيـت آينـده اسـت (I) BSC

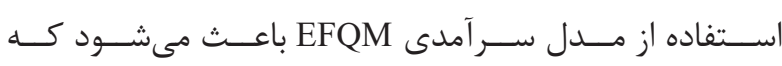

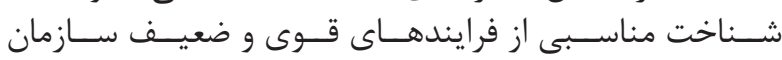

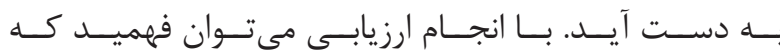

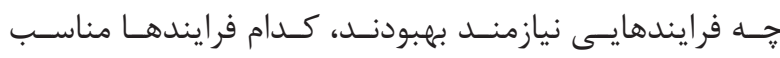

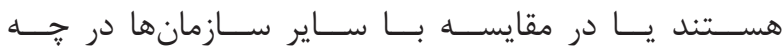

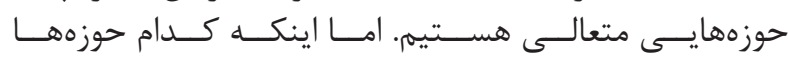

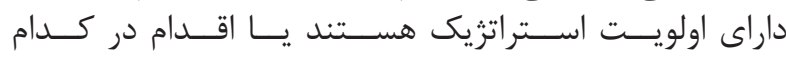

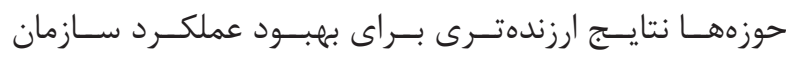

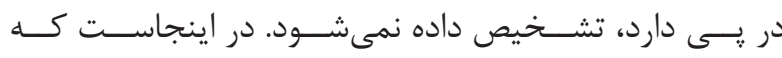

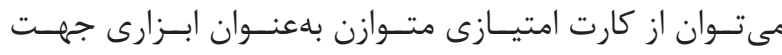

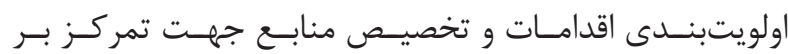

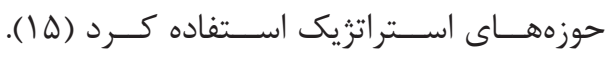

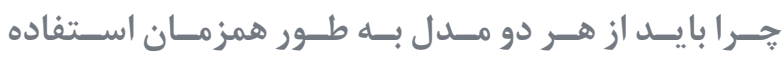
كر د ب

صــرف زمـــان و هزينـــهـ بــراى بهبــود حوزههايسـى كــهـه در

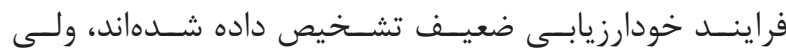

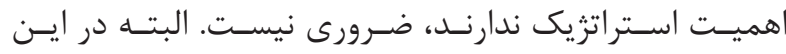

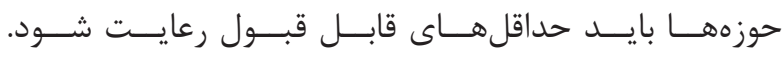

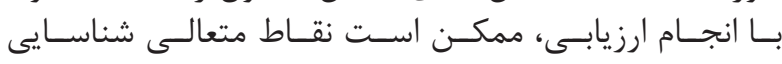

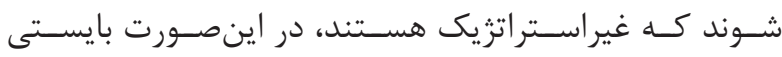




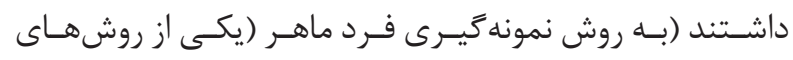

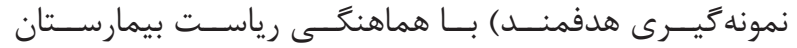

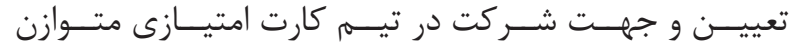

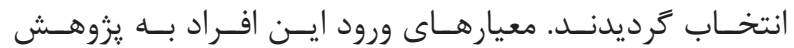

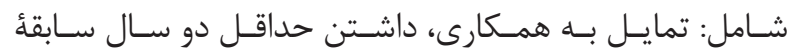

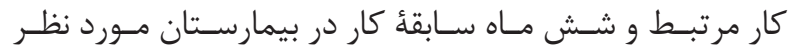

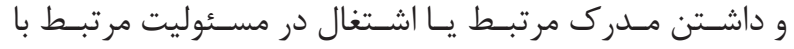

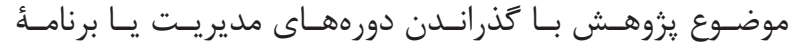

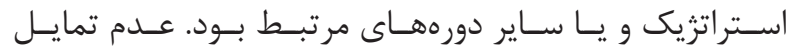

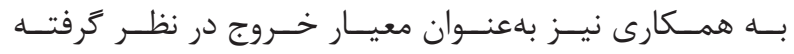

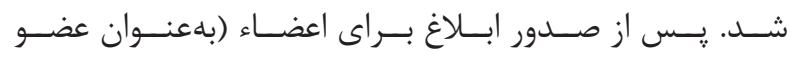

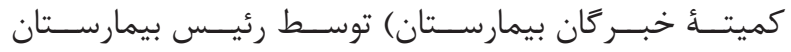

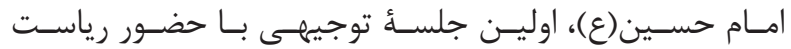

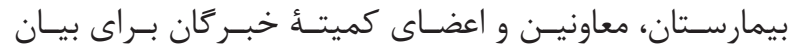

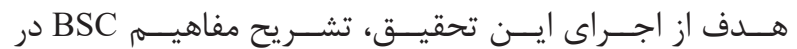

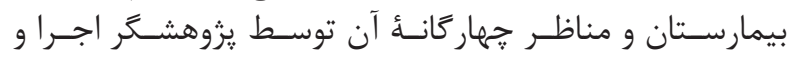

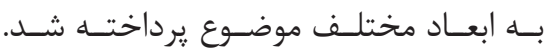

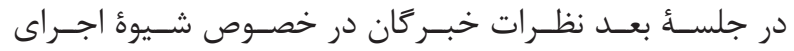

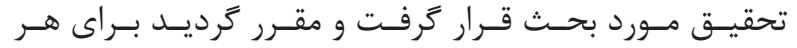

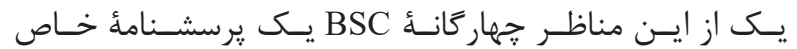

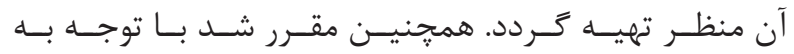

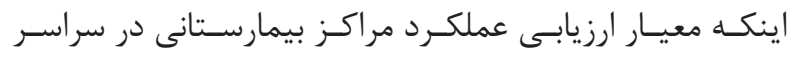

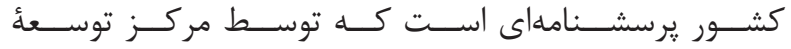

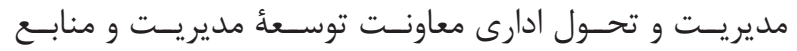

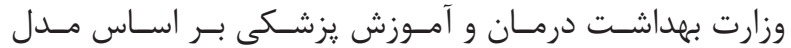

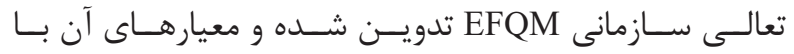

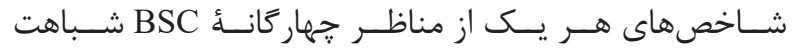

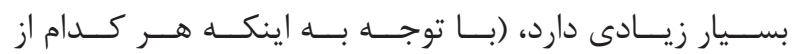

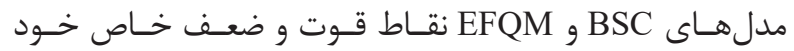

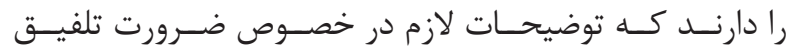

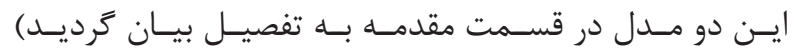
تهيـه كـردد.

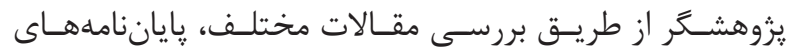

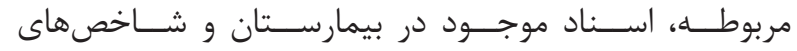

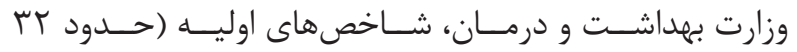

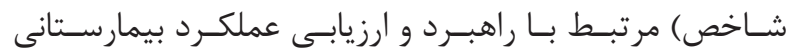

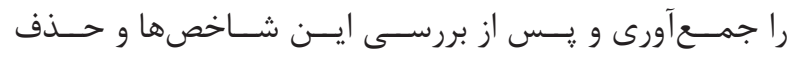

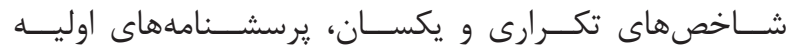

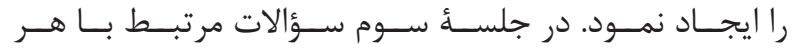

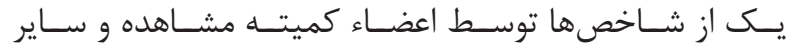

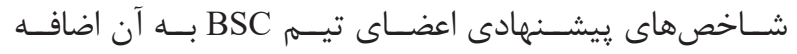

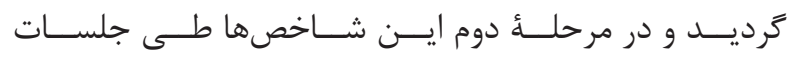

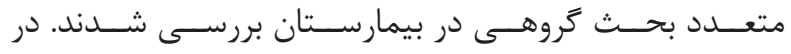

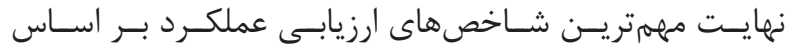

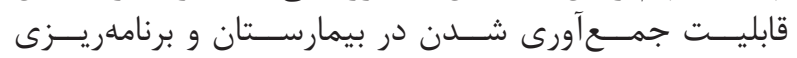

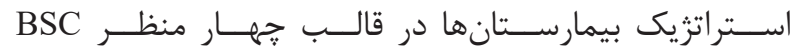

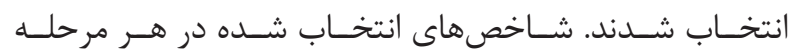

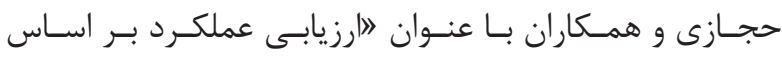

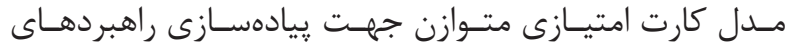

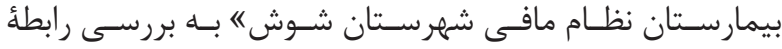

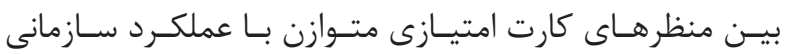

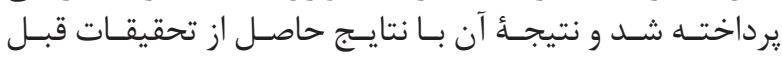

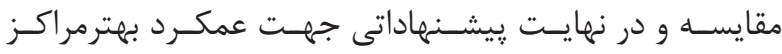

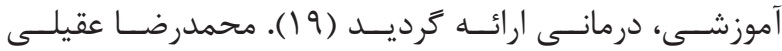

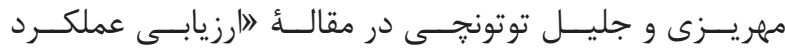

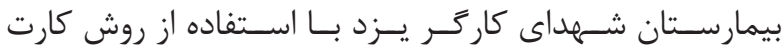

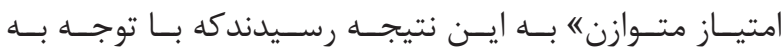

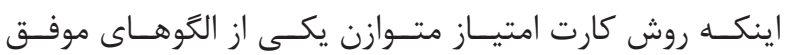

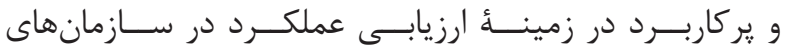

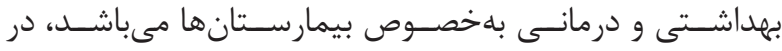

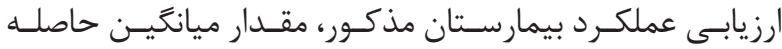

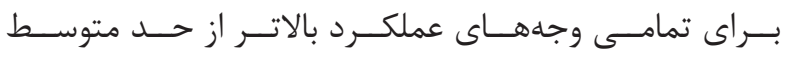

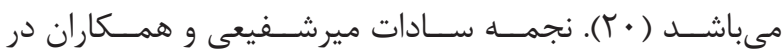

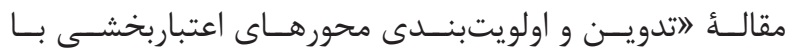

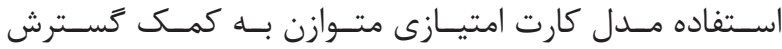

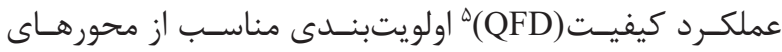

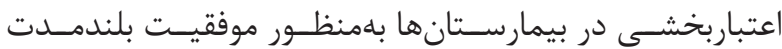

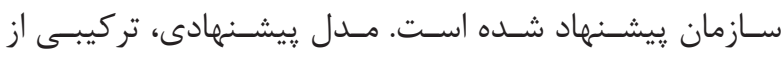

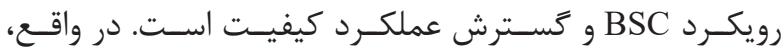

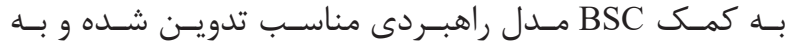

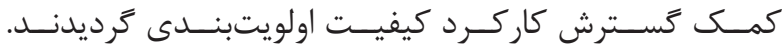

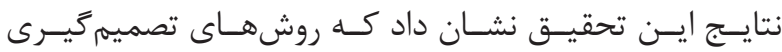

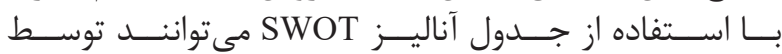

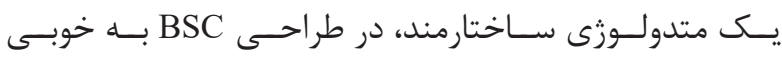

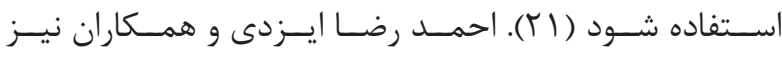

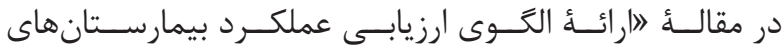

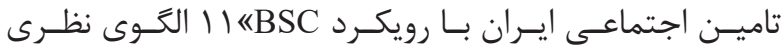

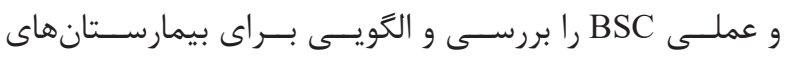
تاميـن اجتماعسى طراحسى كردنـــ (T) (T).

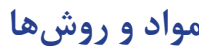

در ايـن مطالعـهـ از روش BSC جهـت شناسـايى و اولويتبندي

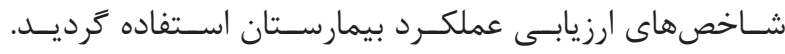

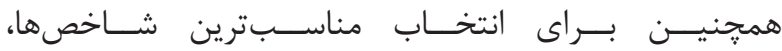

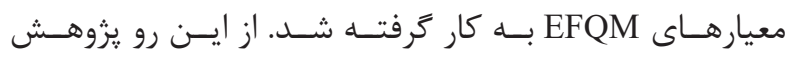

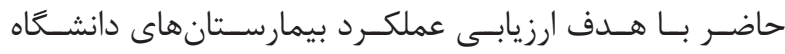

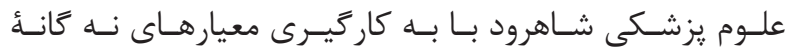

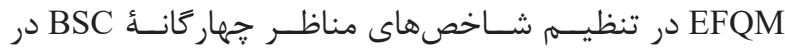

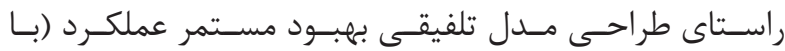

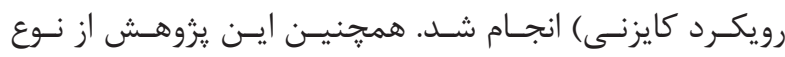

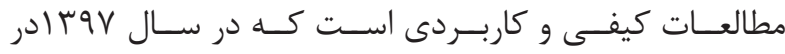

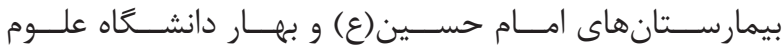

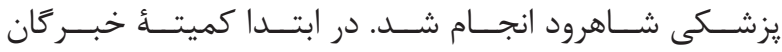

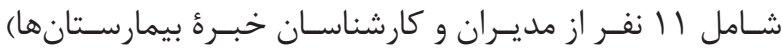

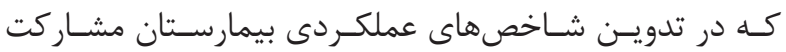




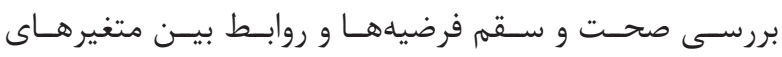

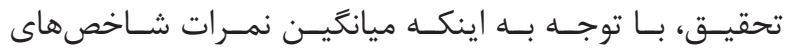

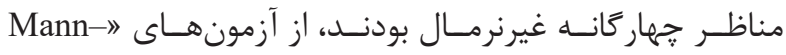

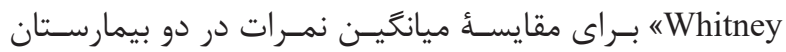

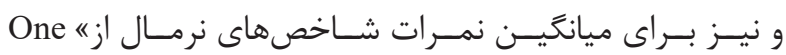
\$sample T test

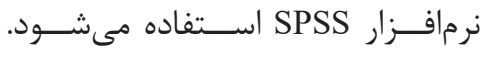

يافتهها

يكـى از اصـول كليـدى در فراينـد BSC ، شنـاسـايى آن دسـته

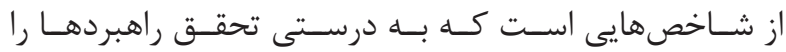

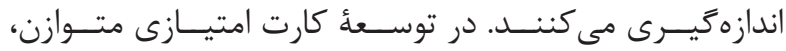

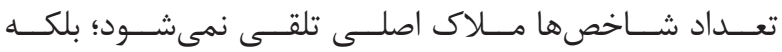

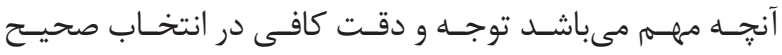

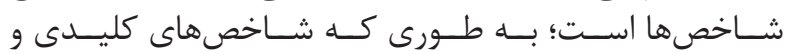

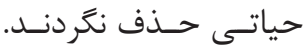

بـــه لحــاظ تعــداد كل شــاخصهاى انتخابـى در ايسـن

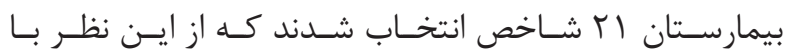

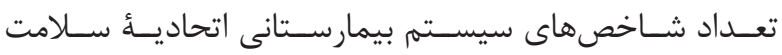

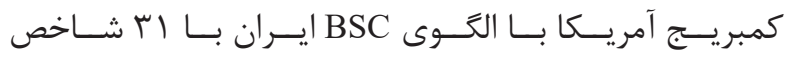

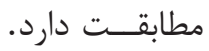

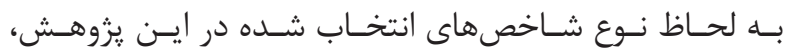

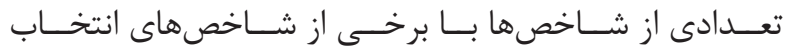

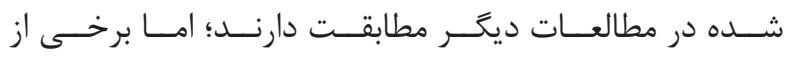

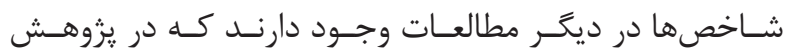

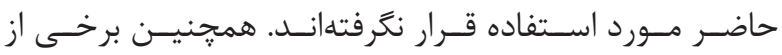

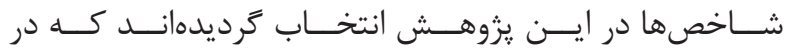

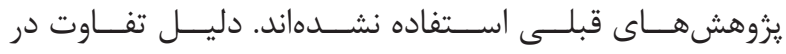

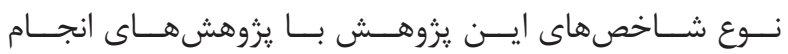

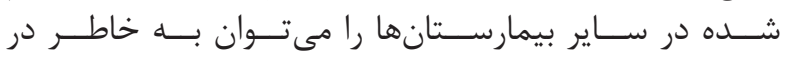

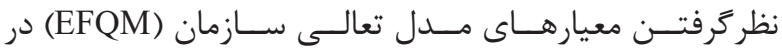

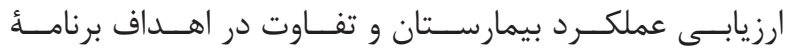

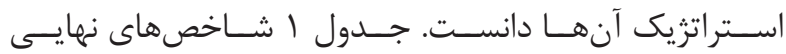

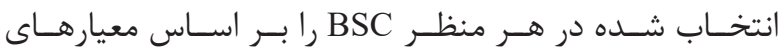

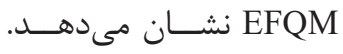

$$
\text { برسى مقادير }
$$

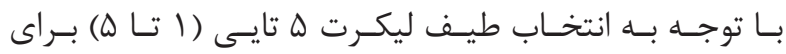

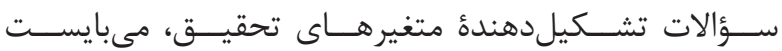

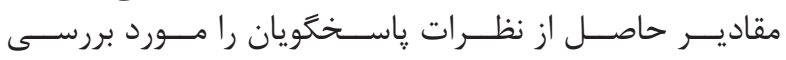

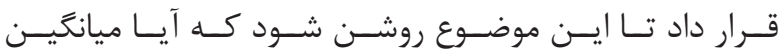

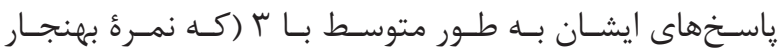

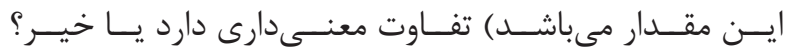

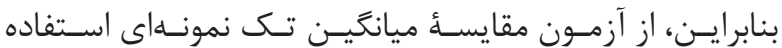

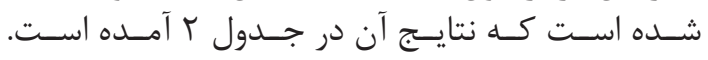

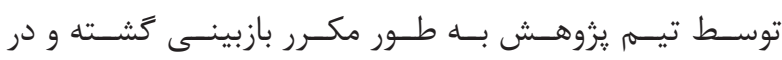

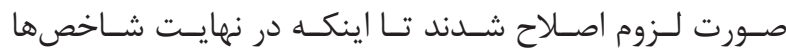

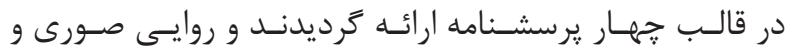

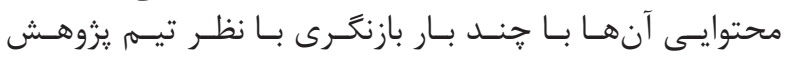

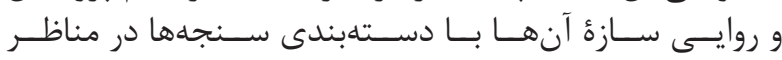

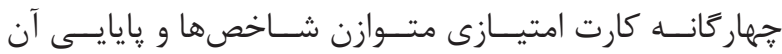

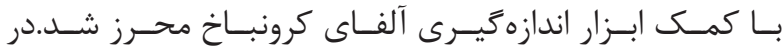

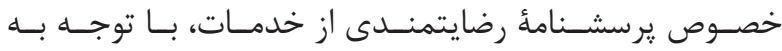

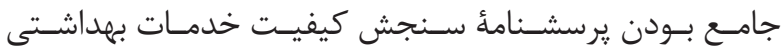

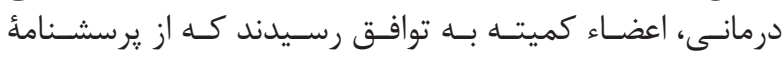

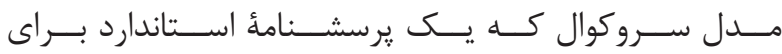

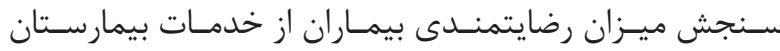
اسـت اسـتفاده خـرد مدرد.

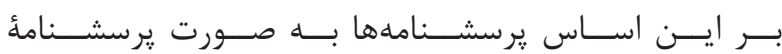

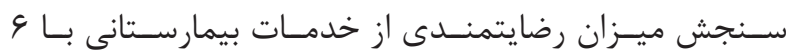

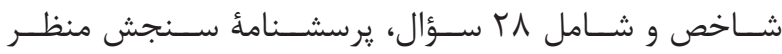

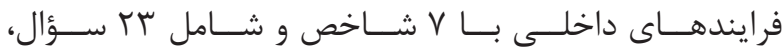

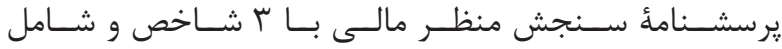

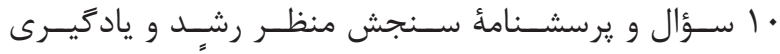

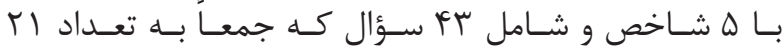

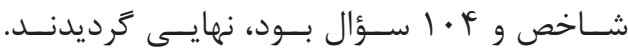

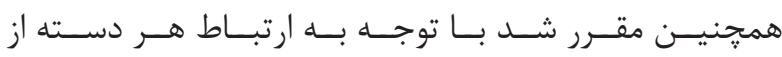

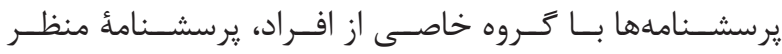

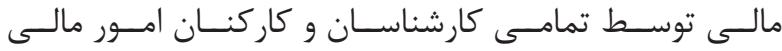

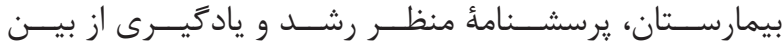

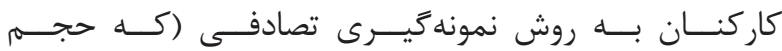

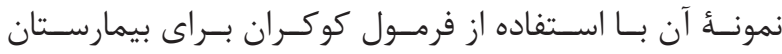

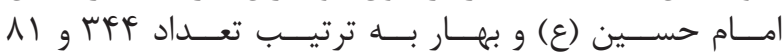

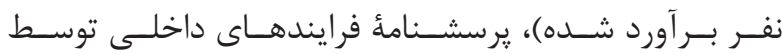

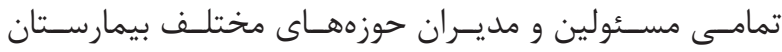

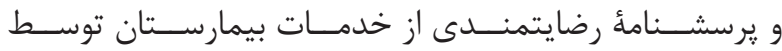

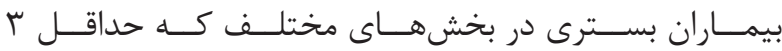

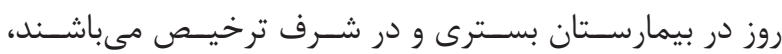

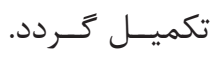

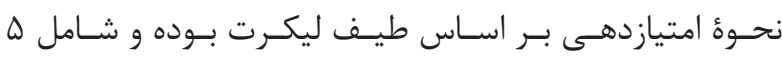

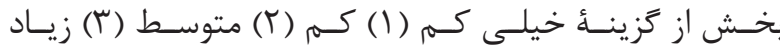

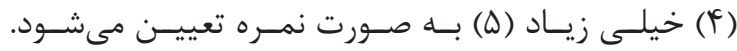

$$
\begin{aligned}
& \text { روش تجزيه و تحليل دادهها }
\end{aligned}
$$

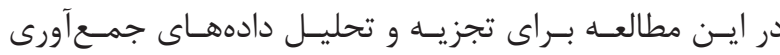

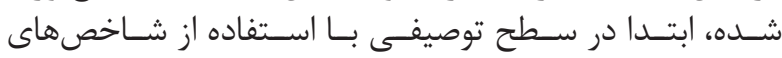

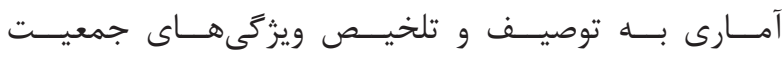

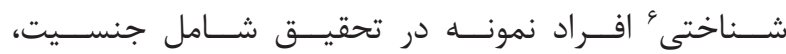

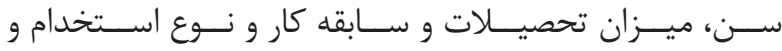

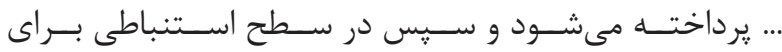




\begin{tabular}{|c|c|c|c|c|}
\hline منظر مشترى & منظر رشد و يادكّيرى & منظر مالى & منظر فرايندهاى داخلى & رديف \\
\hline ملموس و فيزيكى & توسعةُ منابع انسانى & هزينها و مديت منطقى آمدها & مديريت نظاممند فرايندهاى داخلى & 1 \\
\hline قابليت اطمينان & افزايش رضايت كاركنان & وضعيت درآمد & 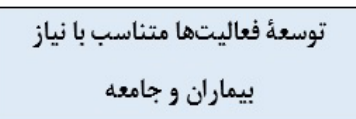 & r \\
\hline ياسخكوئي & افزايش انكَيزش و ايمنى & وضعيت هزينههاى & ايجاد مكانيسمهاى لازم براى توسعة & $r$ \\
\hline تضمين خدمات & ارتقاء فناورى اطلاعات & & توسعهُ مديريت نكههداشت & p \\
\hline همدلى & تشويق نوآورى و حمايت & & شاخصهاى كليدى عملكرد & $\Delta$ \\
\hline 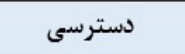 & & & افزايش بهرهورى منابع & 9 \\
\hline & & & بهبود مستمر مديريت زمان فرايند & v \\
\hline
\end{tabular}

\begin{tabular}{|c|c|c|c|c|c|}
\hline Sig.(2-tailed) & اتحراف معيار & مياثَّين & تعداد & ييمارستان & شاخصها \\
\hline$<\cdot / \cdots+1$ &.$/ 9 \mathrm{~V}$ & r/gF & $\Delta 1$ & شماره 1 & \multirow{2}{*}{ مديريت ثظاممند فرايندهاى داخلى } \\
\hline$<\cdot 1 \cdots+$ & $\cdot / 9$. & $r / \Lambda)$ & $r \cdot$ & شماره r & \\
\hline$<+1 \cdots+1$ &.$/ 9 V$ & $r / 91$ & $\Delta 1$ & شماره 1 & \multirow{2}{*}{ توسعة فعاليتها متناسب با نياز بيماران و جامعه } \\
\hline.$/ . r$ & - / 19 & $r / V \cdot$ & $r \cdot$ & شماره r & \\
\hline$<+1 \cdots+$ & $\cdot / V T$ & $r / \Delta$ & $\Delta 1$ & شماره 1 & \multirow{2}{*}{ ايجاد مكاتيسمهاى لازم براى توسعة برون سيارى خدمات } \\
\hline$\cdot / r \Delta q$ &.$/ 90$ & $r / r$ & $r \cdot$ & شماره r & \\
\hline .1 .91 & $\cdot|v|$ & $r / \Lambda)$ & 01 & شماره 1 & \multirow{2}{*}{ توسعة مديريت ثكَهداشت } \\
\hline$<\cdot / \cdots+$ & $\cdot / V 9$ & $\Gamma / \wedge \Delta$ & $r$. & شماره r & \\
\hline .111 &.$/ 199$ & $r / 11$ & $\Delta 1$ & شماره 1 & \multirow{2}{*}{ شاخصهاى كليدى عملكرد } \\
\hline$<\cdot \mid \cdot+1$ & $\cdot / 1 \Delta \Delta$ & $r / 91$ & $r$. & شماره r & \\
\hline$\cdot /+\Delta r$ & .190 & $r / \Lambda)$ & $\Delta 1$ & شماره 1 & \multirow{2}{*}{ افزايش بهرهورى منابع } \\
\hline$<+1 \cdots+1$ & $\cdot / V T$ & r/ar & $r \cdot$ & شماره r & \\
\hline$<\cdot / \cdot \cdot 1$ & $.19 \mathrm{~V}$ & $r / \Delta T$ & $\Delta 1$ & شماره 1 & \multirow{2}{*}{ يهيود مستمر مديريت زمان فرايند } \\
\hline$<+1 \cdots+1$ & - /AT & $r / \Lambda$. & $r \cdot$ & شماره r & \\
\hline$<\cdot \mid \cdot+1$ & $\cdot / \Delta 9$ & T/VT & $\Delta 1$ & شماره & \multirow{2}{*}{ منظر فرايندهاى داخلى } \\
\hline$<+1 \cdots+$ & $\cdot / \mathrm{V} \wedge$ & r/VF & $r \cdot$ & شماره r & \\
\hline$\cdot / \cdot 11$ & $\cdot / V r$ & $\pi /+1$ & 4A & شماره 1 & \multirow{2}{*}{ مديريت منطقى هزينهها و درآمدها } \\
\hline$\cdot 1 \cdot v 8$ &.$/ 4 t$ & $r / 9 V$ & $r \cdot$ & شماره r & \\
\hline . $1 \cdot 41$ & •/AT & $r / \Lambda \Lambda$ & $\uparrow \wedge$ & شماره 1 & \multirow{2}{*}{ وضعيت در آمد بيمارستان } \\
\hline $.1+49$ &.$/ 99$ & $r / 4$. & r. & 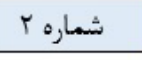 & \\
\hline .1 .91 &.$/ V V$ & $r / 9 V$ & $+\lambda$ & شماره & \multirow{2}{*}{ وضعيت هزينههاى كل بيمارستان } \\
\hline .1 .91 & $\cdot / \Delta F$ & r/9V & $r \cdot$ & 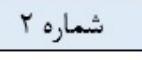 & \\
\hline$\cdot 1 \cdot r \Lambda$ & $\cdot 109$ & $r / 90$ & \&A & شماره & \multirow{2}{*}{ 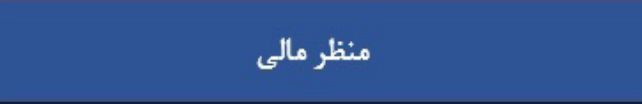 } \\
\hline $1 \cdot 44$ & $\cdot|\Delta|$ & $4 / 11$ & $r \cdot$ & شماره & \\
\hline$<\cdot / \cdot 1$ & .19. & $r / 48$ & $r \Delta \Lambda$ & شماره 1 & \multirow{2}{*}{ توسعة منابع اتساتى } \\
\hline$\cdot 1 \cdot \mathrm{VI}$ & $1 / \cdots$ & $r / T \cdot$ & 11 & شماره r & \\
\hline$<\cdot / \cdot 1$ & $.19 \mathrm{~V}$ & $r / 19$ & $r \Delta \Lambda$ & شماره & \multirow{2}{*}{ افزايش رضايت كاركنان } \\
\hline ./VMG & .191 & $r / \cdot r$ & 11 & شماره r & \\
\hline$<\cdot \mid \cdot+1$ & $1 / \cdot r$ & $r / V \cdot$ & $r \Delta \Lambda$ & شماره 1 & \multirow{2}{*}{ افزايش اثخيزش و ايمنى كاركنان } \\
\hline$<\cdot / \cdot 1$ & $1 / \pi r$ & $\mathrm{r} / \mathrm{gV}$ & 11 & شماره r & \\
\hline$<\cdot / \cdot+1$ & $\cdot / V \Delta$ & T/4 & $r \Delta \Lambda$ & شماره & \multirow{2}{*}{ ارتقاء فناورى اطلاعات } \\
\hline.$/ 1 f$. & $1 / \cdot r$ & $r / I V$ & 11 & شماره r & \\
\hline$<+/ \cdot 1$ & $\cdot|\Lambda|$ & $r / 10$ & $r \Delta \Lambda$ & شماره & \multirow{2}{*}{ تشويق ثوآورى و حمايت از يُوهشهاى كاربردى } \\
\hline \% & $1 / \cdot V$ & T/YG & 11 & شماره r & \\
\hline
\end{tabular}


جدول r- نتايج آزمون تى تك نمونه شاخصهاى "كارت ارزيابى متوازن" با استفاده از معيار هاى "مدل تعالى سازمان".

\begin{tabular}{|c|c|c|c|c|}
\hline$<+/++1$ & $\cdot / \mathrm{VV}$ & $T / T G$ & $r \Delta \Lambda$ & شماره 1 \\
\hline$<+1 *+1$ & $1 / .4 r$ & $r / r 8$ & 11 & شماره r \\
\hline$<+1+* 1$ & $\cdot / V r$ & $r / V V$ & $|V|$ & شماره 1 \\
\hline$<\cdot|\cdot|$ & $\cdot / \Delta Q$ & $f / T \Delta$ & ᄉ. & شماره T \\
\hline$<+/ *+$ & $\cdot / \Lambda f$ & $\Gamma / \Lambda \Delta$ & 194 & شماره 1 \\
\hline$<+1, \cdots 1$ & $\cdot / \Delta V$ & $T / 9 F$ & ᄉ. & شماره r \\
\hline$<* / \cdots+$ & $\cdot / 19$ & $\Gamma / A V$ & $|V|$ & شماره 1 \\
\hline$<+1 *+1$ & $\cdot / V A$ & $r / \Lambda T$ & ᄉ. & شماره r \\
\hline$<\cdot 1 \cdots+$ & $\cdot / 1$. & $f / .$. & $|V|$ & شماره 1 \\
\hline$<+1,+1$ & $\cdot / V F$ & $\Gamma / \Lambda 9$ & 1. & شماره r \\
\hline$<* / \cdots)$ &.$/ 91$ & $r / V I$ & $|V|$ & شماره 1 \\
\hline$<*|\cdot+|$ & . VY & $r / 9 F$ & 1. & شماره r \\
\hline$<* / \cdots)$ & - /Ar & $r / V V$ & $|V|$ & شماره 1 \\
\hline$<+1+* 1$ & $\cdot / V \Delta$ & $f / .$. & 1. & شماره r \\
\hline$<*|\cdots|$ & - $/ \Lambda T$ & $r / \Lambda T$ & 199 & شماره 1 \\
\hline$<\cdot \mid+\cdots)$ & .199 & $r / 9 V$ & ᄉ. & شماره r \\
\hline
\end{tabular}

منظر رشد ويادئيرى

ملموس و فيزيكى

قابليت اطمينان

باسخغُوئى

تضمين خدمات

هos

سترسى

منظر مشترى
بـالا بـودن انـدك آن از متوسـطـ مـورد انتظـار در بيمارسـتان

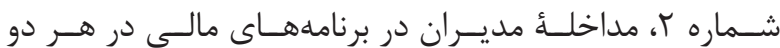

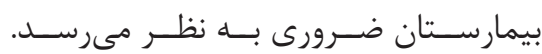

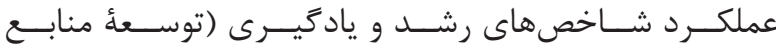

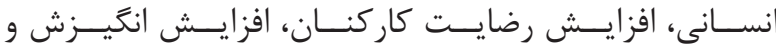

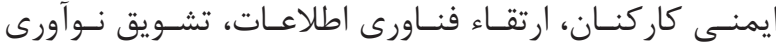

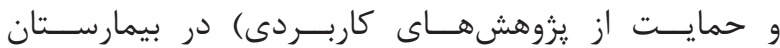

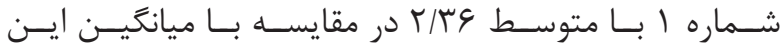

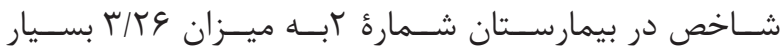

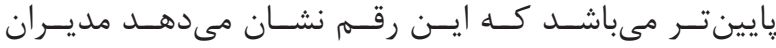

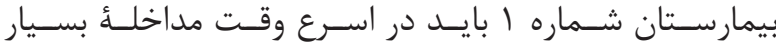

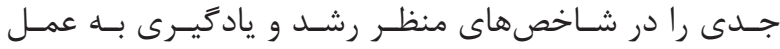

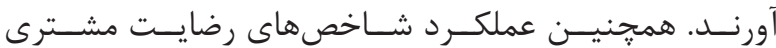

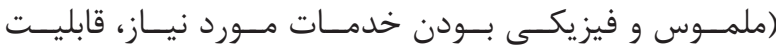

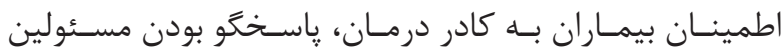

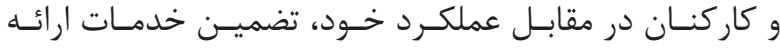

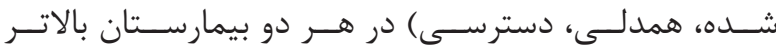

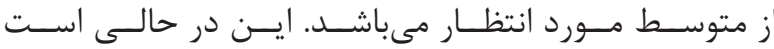

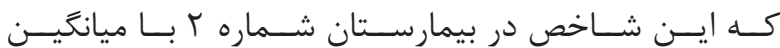

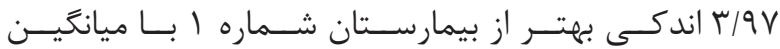

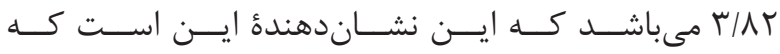

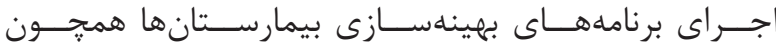

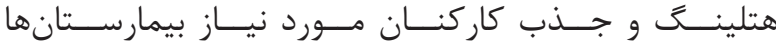

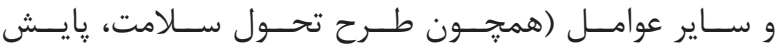

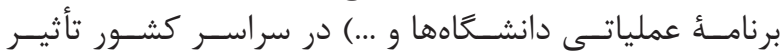

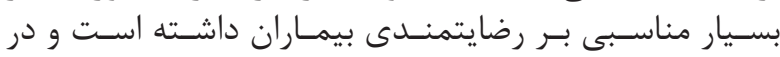

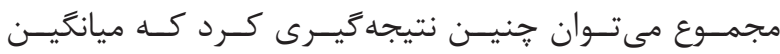

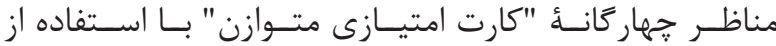

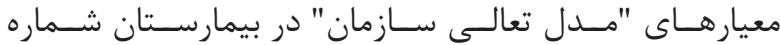

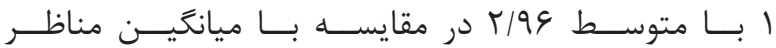

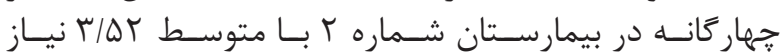

بحث و نتيجه

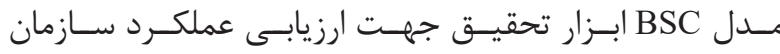

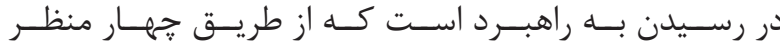

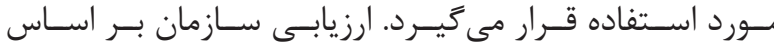

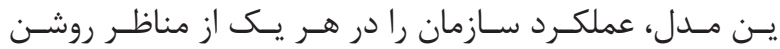

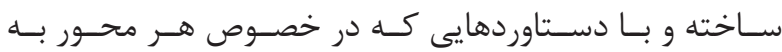

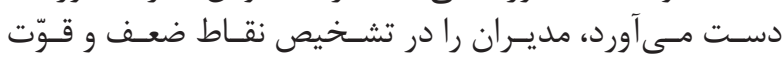

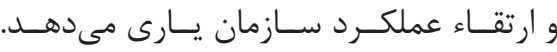

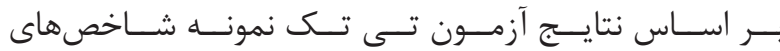

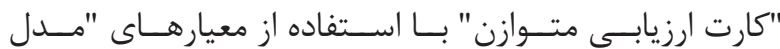

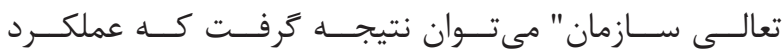

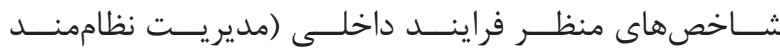

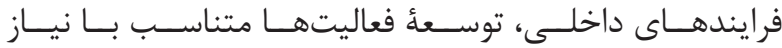

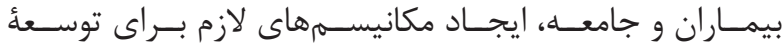

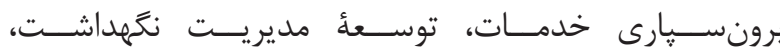

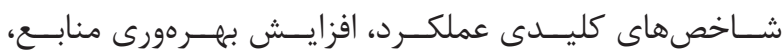

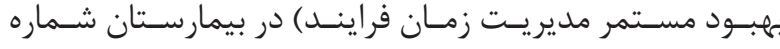

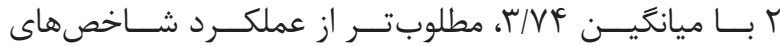

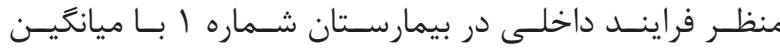

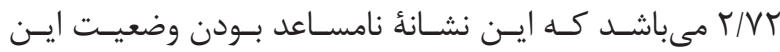

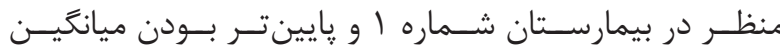

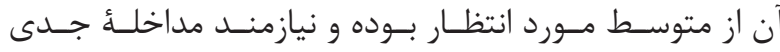

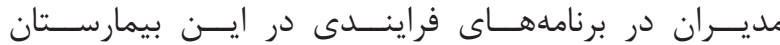

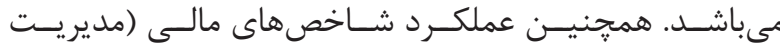

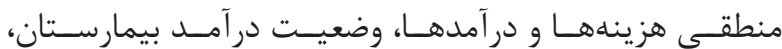

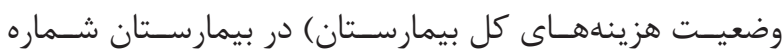

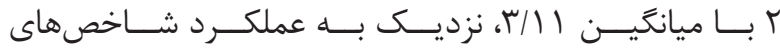

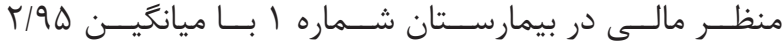

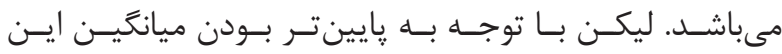

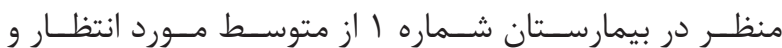




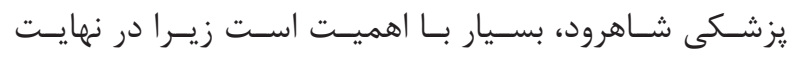

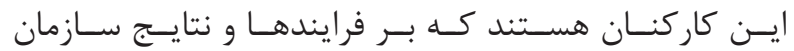

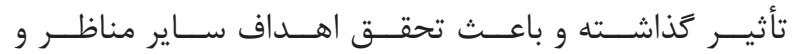

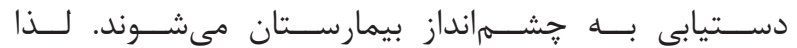

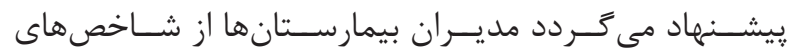

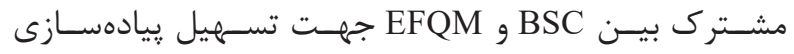

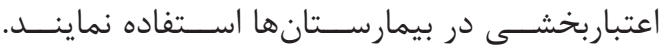
تشكر و قدردانى از همــكارى معاونــت تحقيقــات و فنــاورى دانشـــاه علــوم

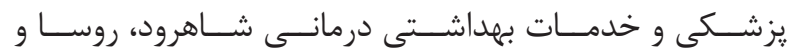

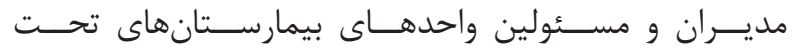

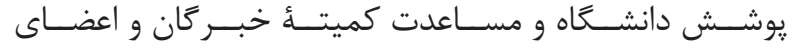

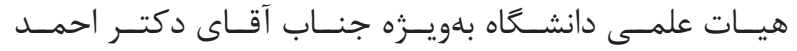

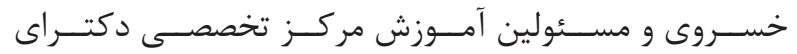

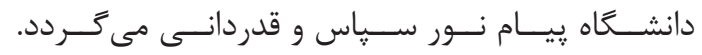

1. Sillup GP, Klimberg R. Assessing the ethics of implementing performance appraisal systems. Journal of Management Development. 2010; 29(1): 38-55.

2. Hamilton KE, Coates V, Kelly B, Boore JR, Cundell $\mathrm{JH}$, Gracey J, et al. Performance assessment in health care providers: A critical review of evidence and current practice. J Nurs Manag. 2007; 15(8):773-91.

3. Mehrolhasani MH, Barfeh T. Performance assessment for teaching hospitals affiliated to kerman university of medical sciences and kerman social security hospitals by using the balanced scorecard. Journal of Sabzevar University of Medical Sciences. 2015; 22(2): 461-71.

4. Hamidian M, Khosravi PN, Abdi M. Evaluation the strategic plan indicators with balanced scorecard approach and hierarchical AHP (case study of iranian tax administration (INTA)). Journal of Tax Research. 2017; 25(34): 171-209.

5. Maleki MR, Nasrollahpour Shirvani SD, Motlagh ME, Tofighi S, Kabir MJ, Jafari N. Necessity of reviewing common performance evaluation methods in vicechancellery for health of universities/schools of medical sciences in iran using excellence models. Hakim Health Systems Research Journal. 2011; 14(1): 50-6.

6. Rojuee M, Ramezani M, Hesari MR, Bor Bor Jafari M. Designing performance evaluation indicators by using ahp and bsc approaches (case of study: social security organization of Mashhad). Social Welfare. 2017; 17(64): 133-60.

7. Fallah SLM. Performance Evaluation By Using Hybrid

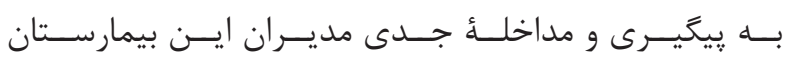

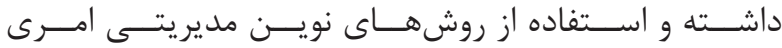

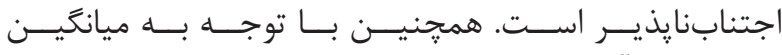

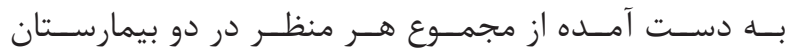

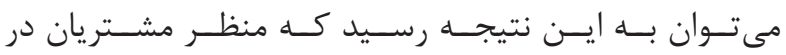

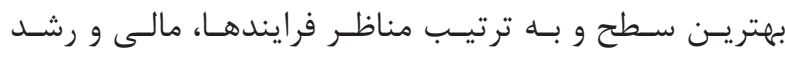

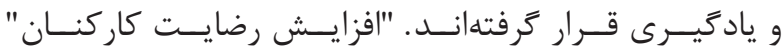

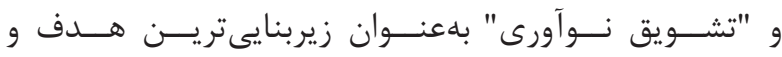

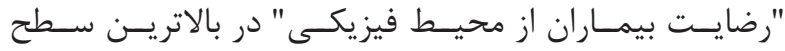

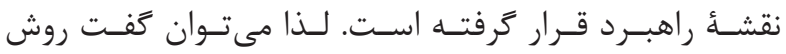

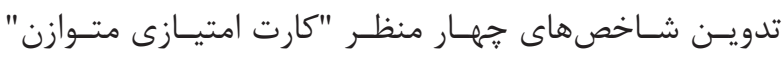

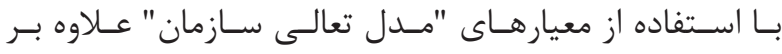

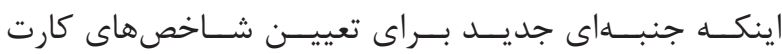

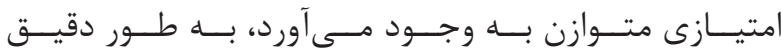

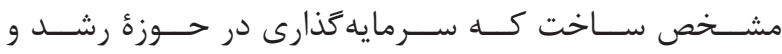

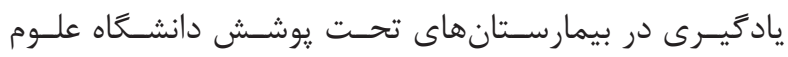

منابع

Method: Bsc, Topsis And Ahp. Journal of Industrial Management. 2013; 5(1): 81-100.

8. Shoghli A, Roshenas K. Application of balance score card (BSC) and analytic hierarchical process (ahp) in assessment of academic departments: a case study in zanjan school of pharmacy. Journal of Medical Education Development. 2016; 9(22): 53-63.

9. Darwish H, Rasooli R, Mobaraki H, Collivand PH. Designing and mapping the strategy map of Khatam-olAnbia hospital from the perspective of the managers and supervisors of the hospitals. Modiriat -e- Farda. 2014; 41(13): 119-30.

10. Darvish H, Kolivand P, Rasouli R, Mobaraki H. Strategic planning model for private hospitals with delphi method: a study in khatam alanbia hospital. Shefaye Khatam. 2014; 2(3): 1-10.

11. Vukomanovic M, Radujkovic M. The balanced scorecard and EFQM working together in a performance management framework in construction industry. Journal of Civil Engineering and Management. 2013; 19(5): 683-95.

12. Gómez Gómez J, Martínez Costa M, Martínez Lorente ÁR. A critical evaluation of the EFQM model. International Journal of Quality \& Reliability Management. 2011; 28(5): 484-502.

13. Badri M, Salehi K. Improving the quality of elementary schools based on the European quality foundation excellence model (EFQM) a case study at Tehran state school. International Conference on 
Management and Social Sciences: Institute of Managers of Idea Capital of Virra. 2015.

14. Hejazi R, Javadi S, Yazdani al-Taba'i SS. Comparison of organizational assessment methods: balanced scorecard (BSC) and excellence model (EFQM). Accounting Research. 2013; 3(2): 1-15.

15. Mohammadi $\mathrm{H}$. The challenges of establishing the excellence model (EFQM) as a framework for improving performance in the administrative system of Iran. Standard and Quality Management. 2017; 7: 48-64.

16. Jafar Nejad A, Ghasemi R, Abdollahi Kakaroodi B, Vahabpour M. Interpretation and interaction of integrated model indicators-efqm-bsc in regional electricity companies. Managing Tomorrow. 2010; 25(9): 23-38.

17. Vafaee-Najar A, Ebrahimipour H, Houshmand E, Zomorrodi-Niat H. Identification and prioritization of hospital performance evaluation indices by combination of balanced scorecard and delphi (montaserieh hospital). International Quarterly Journal. 2018; 21(66): 1-11.

18. Zomorrodi-niat H, Ebrahimipour H, Hooshmand E, Vafaee-najar A. Designing a strategy map with balanced scorecard approach (a case study in montaserieh hospital). Management Strategies in Health System. 2017; 2(3): 173-80.

19. Hejazi S, Mousavi SM, Maki-Nazad Isfahani AR. Performance evaluation based on the BSC model for implementation strategies of nezam mafi hospital city shoush. International Management Conference Elite: Institute of Excellence at Karin Conference. 2016.

20. Aghili Mehrizi MR, Toutonchi J. Evaluation of performance of yazd shohada karegar hospital using balanced scorecard method. International Conference on Management, Economics and Industrial Engineering: Institute of Managers of Idea Capital of Virra. 2015.

21. Mirshafiei NS, Fath ollah M, Ohadi F. Compilation and prioritization of accreditation axes using the balanced scorecard model (bsc) by extending quality function (QFD)-(case study of social security hospitals. First International Conference on Industrial Engineering, Management and Accounting: Alborz Research Institute. 2015.

22. Nasiripour AA, Afshar Kazemi MA, Izadi A. Designing a hospital performance assessment model based on balanced scorecard. HealthMED. 2012; 6: 83-9. 